\title{
TRPV4 Channels: Potential Targets to Reduce the Incidence of Bronchopulmonary Dysplasia (BPD)?
}

\author{
Tanbir Najrana, Juan Sanchez-Esteban* \\ Department of Pediatrics. Alpert Medical School of Brown University. Women \& Infants Hospital of Rhode Island.101 Dudley Street. Providence, RI 02905.USA
}

Received: May 25, 2016; Accepted: June 01, 2016; Published: June 29, 2016

*Corresponding author: Juan Sanchez-Esteban,Department of Pediatrics. Alpert Medical School of Brown University,Women \& Infants Hospital of Rhode Island, 101 Dudley Street. Providence, RI 02905, US Tel: 401-274-1122 ext 47483; Fax: 401-4537571; E-mail: jsanchezesteban@wihri.org

Mechanical forces generated in utero by repetitive breathing movements and by fluid distension are essential to mammalian lung development [1-3]. Paradoxically, many premature infants born with under developed lungs are exposed to excessive, nonphysiological levels of stretch. This may result in ventilatorinduced lung injury, which plays an important role in the pathogenesis of bronchopulmonary dysplasia (BPD), a chronic inflammatory lung disease with serious short- and long-term morbidities [4].

TRPV4 is a $\mathrm{Ca}^{2+}$-permeable cation channel known to play an important role in osmotic and mechanical sensing [5]. In the adult lung,TRPV4 channels control epithelial and endothelial barrier integrity in response to stretch or increased vascular pressure and are a major determinant of ventilator-induced acute lung injury $[6,7]$. However, the role of TRPV4 in injury of under developed lungs is unknown.

Premature infants born during the canalicular stage of lung development have their distal lung epithelium still covered by undifferentiated cells $[8,9]$. Furthermore, these premature lungs are exposed to injury secondary to mechanical ventilation, causing pulmonary edema and inflammation. TRPV4 is expressed in adult lung $[10,11,12]$; however, whether undifferentiated distal epithelial cells express TRPV4 and the response to mechanical injury were unknown. Recent studies from our laboratory have found that TRPV4 is expressed in the fetal lung, and specifically in the bronchial and distal epithelium [13]. Moreover, in vitro experiments in isolated distal epithelial cells found that TRPV4 expression level responded to mechanical signals. This response was gestational-age dependent, being the canalicular stage of lung development the period of gestation more sensitive to mechanical injury [13].

In addition to regulating the integrity of the lung alveolar capillary endothelium $[14,15]$ and maintaining the airway epithelial barrier function [16], TRPV4 has been recently implied as a key mediator of inflammation. TRPV4 inhibitors have potent anti-inflammatory effects by limiting neutrophil and macrophage infiltration, and by blunting pro-inflammatory cytokine and chemokine production [17]. However, the mechanisms underlying these effects are not well-understood. One possibility is that TRPV4 inhibitors act primarily on endothelial and epithelial cells, not only preventing changes in barrier function, but also blocking other $\mathrm{Ca} 2+$ dependent processes, such as the release of cytokines and adhesion molecules or the facilitation of neutrophil transit [18]. Studies from our laboratory found that TRPV4 regulates release of the pro-Inflammatory cytokine IL- 6 in fetal epithelial cells exposed to injurious stretch [13]. Therefore, these investigations provide novel observations that distal fetal epithelial cells are an important source of Inflammatory cytokines, as previously shown in differentiated alveolar type II epithelial cells [19]. Moreover, their release, at least for IL-6, is modulated by TRPV4. All together, these studies suggest that TRPV4 may play a key role in modulating inflammation in the distal epithelium of premature lungs exposed to mechanical injury.

In summary, these data provide the first evidence that TRPV4 channels are present in the epithelium of the fetal lung and could play important role in modulating inflammation. Although TRPV4 inhibitors could be a promising therapeutic strategy for the treatment of BPD in premature infants, more studies are necessaries to carefully evaluate the potential side effects related to their contribution to calcium signaling in normal fetal lung development. Specifically, genetically modified mice in the context of lung injury mediated by neonatal mechanical ventilation or hyperoxia could be effective in vivo models to further investigate the role of TRPV4 in mediating inflammation of premature lungs.

\section{References}

1. Kitterman JA. The effects of mechanical forces on fetal lung growth Clin Perinatol. 1996;23:727-740.

2. Liggins GC. Growth of the fetal lung. J Dev Physiol. 1984;6(3):237-248.

3. Moessinger AC, Harding R, Adamson TM, Singh M, Kiu GT. Role of lung fluid volume in growth and maturation of the fetal sheep lung. J Clin Invest. 1990;86(4):1270-1277.doi:10.1172/JCI114834.

4. Jobe AH, Ikegami M. Mechanisms initiating lung injury in the preterm. Early Hum Dev. 1998;53(1):81-94.

5. Yin J, Kuebler WM. Mechanotransduction by TRP channels: general concepts and specific role in the vasculature. Cell Biochem Biophys. 2010;56(1):1-18. doi: 10.1007/s12013-009-9067-2. 
6. Hamanaka K, Jian MY, Weber DS, Alvarez DF, Townsley MI, Al-Mehdi AB, King JA, Liedtke W, Parker JC. TRPV4 initiates the acute calciumdependent permeability increase during ventilator-induced lung injury in isolated mouse lungs. Am J Physiol Lung Cell Mol Physiol. 2007;293(4):L923-932.

7. Wu S, Jian MY, Xu YC, Zhou C, Al-Mehdi AB, Liedtke W and et al. Ca2+ entry via alpha $1 \mathrm{G}$ and TRPV4 channels differentially regulates surface expression of P-selectin and barrier integrity in pulmonary capillary endothelium. Am J Physiol Lung Cell Mol Physiol. 2009;297(4):L650657. doi:10.1152/ajplung.00015.2009

8. Treutlein B, Brownfield DG, Wu AR, Neff NF, Mantalas GL, Espinoza $\mathrm{FH}$ and et al .Reconstructing lineage hierarchies of the distal lung epithelium using single-cell RNA-seq. Nature. 2014;509(7500):371375. Doi:10.1038/nature13173.

9. Danto SI, Zabski SM, Crandall ED. Late appearance of a type I alveolar epithelial cell marker during fetal rat lung development. Histochemistry. 1994;102(4):297-304.

10. Fernandez-Fernandez JM, Nobles M, Currid A, Vazquez E, Valverde MA. Maxi $\mathrm{K}+$ channel mediates regulatory volume decrease response in a human bronchial epithelial cell line. Am J Physiol Cell Physiol. 2002;283(6):C1705-1714.

11. Delany NS, Hurle M, Facer P, Alnadaf T, Plumpton C, Kinghorn I and et al. Identification and characterization of a novel human vanilloid receptor-like protein, VRL-2. Physiol Genomics. 2001;4(3):165-174.

12. Sidhaye VK, Guler AD, Schweitzer KS, D’Alessio F, Caterina MJ, King LS. Transient receptor potential vanilloid 4 regulates aquaporin-5 abundance under hypotonic conditions. Proc Natl Acad Sci U S A.
2006;103(12):4747-4752.

13. Nayak PS, Wang Y, Najrana T, Priolo LM, Rios M, Shaw SK and et al. Mechanotransduction via TRPV4 regulates inflammation and differentiation in fetal mouse distal lung epithelial cells. Respir Res. 2015;16:60. doi:10.1186/s12931-015-0224-4.

14. Stevens T. Functional and molecular heterogeneity of pulmonary endothelial cells. Proc Am Thorac Soc. 2011;8(6):453-457. doi:10.1513/pats.201101-004MW.

15. Herold S, Gabrielli NM, Vadasz I. Novel concepts of acute lung injury and alveolar-capillary barrier dysfunction. Am J Physiol Lung Cell Mol Physiol. 2013;305(10):L665-681. doi:10.1152/ajplung.00232.2013.

16. Cioffi DL, Lowe K, Alvarez DF, Barry C, Stevens T. TRPing on the lung endothelium: calcium channels that regulate barrier function. Antioxid Redox Signal 2009;11(4):765-776. doi:10.1089/ars.2008.2221

17. Balakrishna S, Song W, Achanta S, Doran SF, Liu B, Kaelberer MM and et al. TRPV4 inhibition counteracts edema and inflammation and improves pulmonary function and oxygen saturation in chemically induced acute lung injury. Am J Physiol Lung Cell Mol Physiol. 2014; 307(2):L158-172. doi:10.1152/ajplung.00065.2014

18. Su WH, Chen HI, Huang JP, Jen CJ. Endothelial $[\mathrm{Ca}(2+)](\mathrm{i})$ signaling during transmigration of polymorphonuclear leukocytes. Blood. 2000;96(12):3816-3822.

19. Hammerschmidt S, Kuhn H, Sack U, Schlenska A, Gessner C, Gillissen A and et al. Mechanical stretch alters alveolar type II cell mediator release toward a proinflammatory pattern. Am J Respir Cell Mol Biol. 2005;33(2):203-210. 